\title{
Gestão escolar democrática: desafios e perspectivas
}

\author{
Democratic school management: challenges and prospects
}

\section{Gestión escolar democrática: desafios y perspectivas}

\author{
Dirléia Fanfa Sarmento' \\ Universidade La Salle, Programa de Pós-graduação, Professora; CNPq, Pesquisadora \\ https://orcid.org/0000-0001-7328-6343 \\ Jardelino Menegat ${ }^{2}$ \\ Universidade Católica de Petrópolis, Programa de Pós-graduação, Professor; CNPq, \\ Pesquisador \\ https://orcid.org/0000-0003-4003-8882
}

Resumo: As reflexões ora apresentadas são decorrentes de uma pesquisa teórica de cunho documental, cuja centralidade analítico-discursiva focaliza o direito à educação de qualidade e seus modos de efetivação em diferentes contextos. Neste texto, fazemos um recorte sobre o princípio constitucional da gestão democrática, analisando as decorrências de tal princípio para a gestão escolar. 0 corpus investigativo está composto por dispositivos legais que abordam o tema, estabelecendo-se um diálogo com as produções de autores, como Libâneo, Oliveira e Toschi, Medeiros e Luce e Lück. Por meio da Técnica de Análise de Conteúdo, definimos quatro eixos temáticos estabelecidos com base na incursão analítica realizada no corpus investigativo, a saber: concepção de gestão democrática, equipe de gestão escolar, instâncias de participação, organização e planejamento da ação gestora. Os principais achados do estudo são sistematizados em dois tópicos: desafios e perspectivas. Quanto aos desafios, destacamos a necessidade da consolidação de uma cultura escolar pautada pelo diálogo, pela participação e pela corresponsabilidade dos que integram uma comunidade educativa. No que se refere às perspectivas, enfatizamos que a gestão democrática pode se constituir numa dimensão mobilizadora das competências dos diversos atores que compõem a comunidade educativa, contribuindo para que haja sinergia entre eles, tendo em vista a consolidação da educação de qualidade.

Palavras-chave: Gestão democrática. Gestão escolar. Educação de qualidade.

Abstract: The reflections presented here are the result of a theoretical research of documentary nature, whose discursive analytical centrality focuses on the right to quality education and its modes

Pós-doutora em Educação pela Universidade do Algarve; Doutora em Educação pela Universidade Federal do Rio Grande do Sul.

Pós-doutor em Educação pela Universidade Federal Fluminense; Doutor em Educação pela Universidade La Salle. 
of realization in different contexts. In this text, we make a cut with respect to the constitutional principle of management, analyzing the consequences of such a principle for school management. The investigative corpus is composed of legal devices that approach this theme establishing a dialogue with the productions of Libâneo, Oliveira e Toschi, Medeiros e Luce e Lück. Through the Content Analysis Technique, we defined four thematic axes which were established based on the analytical incursion made in the investigative corpus, namely: conception of democratic management, school management team, instances of participation, organization and planning of management action. The main findings of the study are systematized in two topics: challenges and perspectives. As for the challenges we highlight the need to consolidate a school culture based on dialogue, participation and co-responsibility of those who make up an educational community. Regarding the perspectives, we emphasize that democratic management can be a mobilizing dimension of the competences of the various actors that make up the educational community, contributing to the synergy between them, in order to consolidate a quality education.

Keywords: Democratic management. School management. Quality education.

Resumen: Las reflexiones que ahora presentamos son fruto de una investigación teórica de tipo documental, cuya centralidad analítica discursiva se enfoca en el derecho de la educación de calidad y sus modos de hacerla efectiva en diferentes contextos. En este texto, hacemos un estudio sobre el principio constitucional de la gestión democrática, analizando las consecuencias de tal principio para la gestión escolar. El corpus de la investigación se compone por las disposiciones legales que abordan el tema del estableciéndose un diálogo con las producciones de autores tales como Libâneo, Oliveira y Toschi, Medeiros e Luce y Lück. Por medio de la técnica de Análisis de Contenido, definimos cuatro ejes temáticos establecidos con base en la incursión analítica realizada en el corpus de la investigación, a saber: concepto de gestión democrática, equipo de gestión escolar, instancias de participación, organización y planificación de la actividad gestora. Los principales hallazgos del estudio se sistematizan en dos tópicos: desafios y perspectivas. En cuanto a los desafíos destacamos la necesidad de la consolidación de una cultura escolar pautada por el diálogo, por la participación y por la corresponsabilidad de quienes integran una comunidad educativa. En lo que se refiere a las perspectivas, enfatizamos que la gestión democrática se puede constituir en una dimensión movilizadora de competencias de los diferentes actores que la componen la comunidad educativa, constituyendo para que haya una sinergia entre ellas, teniendo en vista la consolidación de la educación de calidad. Palabras clave: Gestión democrática. Gestión escolar. Educación de calidad.

Recebido em 30 de outubro de 2019 Aceito em 23 de junho de 2020 Publicado em 19 de agosto de 2020 


\section{INTRODUÇÃO}

0 ideário da gestão escolar democrática foi sendo construído gradativamente, articulado a um conjunto de lutas e transformações nos cenários social, histórico, econômico e político do País. Especialmente a partir da década de 1980, "no bojo da ampla luta pela democracia que se formula, entre nós, a noção de gestão democrática da educação, compreendendo a gestão democrática na educação." (MEDEIROS; LUCE, 2006, p. 15, grifo do autor).

Com a promulgação da Constituição da República Federativa do Brasil (BRASIL, 1988) se firma o princípio constitucional da gestão democrática, o qual é reiterado na Lei de Diretrizes e Bases da Educação Nacional (BRASIL, 1996). Alinhados com essa Lei, as Diretrizes Curriculares Nacionais Gerais para a Educação Básica (BRASIL, 2010a), revisadas em 2013 (BRASIL, 2013), e o Plano Nacional de Educação (BRASIL, 2014), entre outros dispositivos, reafirmam tal princípio, tanto no âmbito da gestão educacional quanto da gestão escolar.

Consideramos oportuno destacar que, ao nos referir à gestão educacional, temos presente a gestão da educação em seu nível macro, cuja responsabilidade está sob a União, os Estados, o Distrito Federal e os Municípios, que organizam os respectivos sistemas de ensino (BRASIL, 1996). Nas palavras de Lück (2006, p. 25):

[...] a gestão educacional corresponde à área de atuação responsável por estabelecer o direcionamento e a mobilização capazes de sustentar e dinamizar o modo de ser e de fazer dos sistemas de ensino e das escolas, para realizar ações conjuntas associadas e articuladas, visando ao objetivo comum da qualidade do ensino e seus resultados.

Com relação à gestão escolar, entendemos que esta se relaciona à gestão de uma determinada comunidade escolar, em suas dimensões administrativas e pedagógicas, tendo como principal finalidade assegurar que os objetivos educacionais se consolidem (LÜCK, 2009; LIBÂNEO; OLIVEIRA; TOSCH, 2003).

Em uma visão sistêmica, ambos os níveis de gestão se encontram interrelacionados, pois no nível macro (da gestão educacional) são emanadas as políticas, os programas, os planos e as ações educacionais, as quais deverão ser observadas no nível micro (na gestão de cada escola). Além disso, tratando-se da gestão escolar, é preciso termos presente que as escolas são organizações inseridas num contexto sociocultural, político-econômico e científico que também interfere no seu modus operandi. Portanto, 
Os vários sistemas existentes na sociedade articulam-se e relacionam-se com o sistema educacional. Sofrem influência dele e o influenciam. Os vários tipos de contatos, de inter-relações, de conflitos entre os vários sistemas são fruto das condições históricas, ideológicas, econômicas e políticas existentes na sociedade - o que significa que, em certos momentos, um ou outro sistema passa a ter influência maior sobre os demais. (LIBÂNEO; OLIVEIRA; TOSCH, 2003, p. 229).

Diante do exposto, neste texto fazemos um recorte no que se refere ao princípio constitucional da gestão democrática, analisando as decorrências de tal princípio para a gestão escolar. De acordo com Lück (2009, p. 23):

A gestão escolar constitui uma das áreas de atuação profissional na educação destinada a realizar o planejamento, a organização, a liderança, a orientação, a mediação, a coordenação, o monitoramento e a avaliação dos processos necessários à efetividade das ações educacionais orientadas para a promoção da aprendizagem e formação dos alunos. [...] como área de atuação, constitui-se, pois, em um meio para a realização das finalidades, os princípios, as diretrizes e os objetivos educacionais orientadores da promoção de ações educacionais com qualidade social [...]

Em termos de estrutura textual, inicialmente apresentamos o foco temático. $\mathrm{Na}$ sequência, descrevemos a abordagem metodológica, seguida pela análise e interpretação dos dados. Por fim, nas considerações finais, retomamos os principais achados do estudo.

\section{ABORDAGEM METODOLÓGIICA}

As reflexões ora apresentadas são decorrentes de uma pesquisa teórica de cunho documental (MOROZ; GIANFALDONI, 2006; GIL, 2008; GODOY, 1995) que focaliza o direito à educação de qualidade (ORGANIZAÇÃO DAS NAÇÕES UNIDAS, 1948; ORGANIZAÇÃO DAS NAÇÕES UNIDAS PARA A EDUCAÇÃO, A CIÊNCIA E A CULTURA, 1990, 2001, 2015a, 2015b; ORGANIZAÇÃO DOS ESTADOS IBERO-AMERICANOS PARA A EDUCAÇÃO, A CIÊNCIA E A CULTURA, 2012; BRASIL, 1988, 1990, 1996, 2009, 2010a, 2010b, 2010c, 2013, 2014, 2017) e seus modos de efetivação em diferentes contextos. Neste texto, fazemos um recorte da análise documental de dispositivos legais nacionais, refletindo sobre o proposto em tais dispositivos acerca da gestão democrática e suas decorrências para a gestão escolar.

Entendemos que a gestão escolar democrática é um dos fatores que contribuem para a oferta de educação de qualidade, pois viabiliza por meio das diversas instâncias de 
participação a corresponsabilidade dos integrantes da comunidade escolar com a elaboração e a efetivação do projeto educativo de uma determinada escola. Lück (2016, p. 28) assevera que:

A qualidade do ensino, tão necessária e preconizada para que nossa população possa alcançar melhores niveis de qualidade de vida e maior competência no enfrentamento de seus anseios de desenvolvimento, passa pela garantia de variados processos e condições interligados, envolvendo múltiplos aspectos internos e externos à escola e aos sistemas de ensino.

Ao falarmos em educação de qualidade, temos presente a concepção apresentada no Parecer CNE/CEB n. 7/2010:

0 conceito de qualidade na escola, numa perspectiva ampla e basilar, remete a uma determinada ideia de qualidade de vida na sociedade e no planeta Terra. Inclui tanto a qualidade pedagógica quanto a qualidade política, uma vez que requer compromisso com a permanência do estudante na escola, com sucesso e valorização dos profissionais da educação. Trata-se da exigência de se conceber a qualidade na escola como qualidade social, que se conquista por meio de acordo coletivo. Ambas as qualidades pedagógica e política - abrangem diversos modos avaliativos comprometidos com a aprendizagem do estudante, interpretados como indicações que se interpenetram ao longo do processo didático-pedagógico, o qual tem como alvo o desenvolvimento do conhecimento e dos saberes construídos histórica e socialmente. (BRASIL, 2010a).

Elegemos como dispositivos legais constituintes do corpus investigativo a Constituição da República Federativa do Brasil (BRASIL, 1988), a Lei de Diretrizes e Bases da Educação Nacional (BRASIL, 1996), as Diretrizes Curriculares Nacionais Gerais para a Educação Básica (BRASIL, 2010b) e o Plano Nacional de Educação (BRASIL, 2014). Segundo Sá-Silva, Almeida e Guindani (2009, p. 2):

0 uso de documentos em pesquisa deve ser apreciado e valorizado. A riqueza de informações que deles podemos extrair e resgatar justifica o seu uso em várias áreas das Ciências Humanas e Sociais porque possibilita ampliar o entendimento de objetos cuja compreensão necessita de contextualização histórica e sociocultural.

Igualmente, ao utilizar documentos como fonte de coleta de dados, corroboramos a posição de Godoy (1995, p. 23), quando a autora menciona que "A escolha dos documentos não é um processo aleatório, mas se dá em função de alguns propósitos, ideias ou hipóteses." 
Por isso, selecionamos os referidos dispositivos legais por eles serem os principais documentos reguladores da ação educativa na Educação Básica. No caso das Diretrizes Curriculares Nacionais Gerais para a Educação Básica (BRASIL, 2010b), é com base nesse documento que são formuladas as Diretrizes Curriculares da Educação Infantil e as Diretrizes Curriculares do Ensino Fundamental.

Para a análise dos dispositivos selecionados, utilizamos a Técnica de Análise de Conteúdo, proposta por Bardin (2011). A observação das etapas previstas por essa Técnica auxilia o pesquisador no processo de organização, de categorização e de tratamento das informações presentes nas respostas de entrevistas, questionários e em documentos, entre outros. Considerando os procedimentos indicados por Bardin (2011), definimos quatro eixos temáticos estabelecidos com base na incursão analítica realizada no corpus investigativo, tendo como referência questões que nos mobilizaram a tal estudo, como qual a concepção de gestão democrática presente nos dispositivos legais que orientam a ação educativa na Educação Básica? Como se constitui uma equipe de gestão escolar numa perspectiva democrática? Quais as instâncias de participação numa comunidade escolar que busca efetivar o princípio da gestão democrática? De que forma organizar e planejar a ação gestora? A reflexão acerca de cada um dos eixos temáticos norteadores da análise e interpretação dos resultados é foco da próxima seção.

\section{ANÁLISE E INTERPRETAÇÃO DOS RESULTADOS}

Conforme referido, nesta seção temos como foco a apresentação das reflexões oriundas da análise e interpretação dos resultados do estudo que realizamos, as quais foram organizadas em quatro eixos temáticos, a saber: a) concepção de gestão democrática; b) equipe de gestão escolar; c) instâncias de participação; e d) organização e planejamento da ação gestora.

De acordo com a Constituição da República (BRASL, 1988) e a Lei de Diretrizes e Bases da Educação Nacional (BRASIL, 1996), a gestão democrática se constitui num dos princípios a serem observados no ensino ministrado na Educação Básica. De forma articulada à gestão democrática, encontram-se a oportunidade igualitária de acesso e permanência; a liberdade de aprender, ensinar e pesquisar, respeitando-se o pluralismo de ideias e concepções pedagógicas, entre outros (BRASIL, 1988, 1996).

No artigo 14 da Lei de Diretrizes e Bases da Educação Nacional é estabelecida a competência dos sistemas de ensino em definir as normas da gestão democrática, observandose os seguintes princípios: "I - participação dos profissionais da educação na elaboração do 
projeto pedagógico da escola; II - participação das comunidades escolar e local em conselhos escolares ou equivalentes." (BRASIL, 1996). Na sequência, o artigo 15 dessa Lei destaca que: “Os sistemas de ensino assegurarão às unidades escolares públicas de educação básica que os integram progressivos graus de autonomia pedagógica e administrativa e de gestão financeira, observadas as normas gerais de direito financeiro público." (BRASIL, 1996).

As Diretrizes Curriculares Nacionais Gerais para a Educação Básica enfatizam que o princípio da gestão democrática deve se efetivar por meio da "Art. $7^{\circ}$ [...] institucionalização do regime de colaboração entre União, Estados, Distrito Federal e Municípios, no contexto da estrutura federativa brasileira, em que convivem sistemas educacionais autônomos", a qual é "possibilitada por um Sistema Nacional de Educação, no qual cada ente federativo, com suas peculiares competências, é chamado a colaborar para transformar a Educação Básica em um sistema orgânico, sequencial e articulado." (BRASIL, 2010b). As Diretrizes indicam, também, que os responsáveis pela garantia da consolidação desse princípio no contexto escolar são ○ "Art. $4^{\circ}$ [...] poder público, a família, a sociedade e a escola." (BRASIL, 2010b).

0 Plano Nacional de Educação apresenta como uma de suas diretrizes, a "Art. $2^{\circ}$ [...] promoção do princípio da gestão democrática da educação pública." (BRASIL, 2014). Esta diretriz se desdobra nas metas 7 (qualidade da Educação Básica) e na 19 (efetivação da gestão democrática).

No contexto escolar, a gestão está sob a responsabilidade de um profissional da educação, cuja formação, segundo a Lei de Diretrizes e Bases da Educação Nacional, "Art. 64 [...] será feita em cursos de graduação em pedagogia ou em nível de pós-graduação." (BRASIL, 1996).

Com relação à organização e ao planejamento da ação gestora, encontramos nos Artigos 12 e 13 da Lei de Diretrizes e Bases da Educação Nacional (BRASIL, 1996) alguns indicativos, como: a elaboração da proposta pedagógica da escola com a participação dos integrantes da comunidade escolar; a administração dos recursos humanos, materiais e financeiros; a mobilização da família, promovendo a integração desta com a comunidade escolar; o zelo pela aprendizagem e a promoção de um ambiente seguro.

As Diretrizes Curriculares Nacionais Gerais para a Educação Básica explicitam que:

Art. 54 É pressuposto da organização do trabalho pedagógico e da gestão da escola conceber a organização e a gestão das pessoas, do espaço, dos processos e procedimentos que viabilizam o trabalho expresso no projeto político-pedagógico e em planos da escola, em que se conformam as condições de trabalho definidas pelas instâncias colegiadas. (BRASIL, 2010b). 
No parágrafo $2^{\circ}$ do artigo supracitado fica evidenciada, também, a obrigatoriedade da gestão democrática no ensino público, “Art. 54 § $2^{\circ}$ [...] o que implica decisões coletivas que pressupõem a participação da comunidade escolar na gestão da escola e a observância dos princípios e finalidades da educação." (BRASIL, 2010b). Dessa forma,

Art. $54 \S 3^{\circ}$ No exercício da gestão democrática, a escola deve se empenhar para constituir-se em espaço das diferenças e da pluralidade, inscrita na diversidade do processo tornado possivel por meio de relações intersubjetivas, cuja meta é a de se fundamentar em princípio educativo emancipador, expresso na liberdade de aprender, ensinar, pesquisar e divulgar a cultura, o pensamento, a arte e o saber. (BRASLL, 2010b).

As Diretrizes conferem ao Projeto Político-Pedagógico um papel de suma importância, ao considerar que ele "Art. $43^{\circ}$ [...] representa mais do que um documento, sendo um dos meios de viabilizar a escola democrática para todos e de qualidade social." (BRASIL, 2010b). Portanto, a participação da comunidade escolar é fundamental na elaboração, acompanhamento e avaliação da execução desse Projeto. Inclusive, um dos aspectos a serem contemplados nesse documento são: “Art. 44 - VI [...] os fundamentos da gestão democrática, compartilhada e participativa (órgãos colegiados e de representação estudantil)." (BRASIL, 2010b). Desse ponto de vista,

Art. $43 \S 1^{\circ}$ A autonomia da instituição educacional baseia-se na busca de sua identidade, que se expressa na construção de seu projeto pedagógico e do seu regimento escolar, enquanto manifestação de seu ideal de educação e que permite uma nova e democrática ordenação pedagógica das relações escolares. (BRASLL, 2010b).

Além do Projeto Político-Pedagógico (ou Proposta Pedagógica), as Diretrizes salientam o papel da comunidade escolar na discussão e na aprovação do Regimento Escolar, sendo que este documento

Art. 45 [...] trata da natureza e da finalidade da instituição, da relação da gestão democrática com os órgãos colegiados, das atribuições de seus órgãos e sujeitos, das suas normas pedagógicas, incluindo os critérios de acesso, promoção, mobilidade do estudante, dos direitos e deveres dos seus sujeitos: estudantes, professores, técnicos e funcionários, gestores, familias, representação estudantil e função das suas instâncias colegiadas. (BRASIL, 2010b). 
A menção à necessidade de um plano de gestão é feita no artigo 52 das Diretrizes (BRASIL, 2010b), quando se refere à questão da avaliação institucional, a qual deve ser prevista no Projeto Político-Pedagógico. Por fim, é possível constatar a relação entre a gestão democrática e a organização curricular, sendo que ela

Art. 55 [...] constitui-se em instrumento de horizontalização das relações, de vivência e convivência colegiada, superando o autoritarismo no planejamento e na concepção e organização curricular, educando para a conquista da cidadania plena e fortalecendo a ação conjunta que busca criar e recriar o trabalho da e na escola [...] (BRASIL, 2010b).

Para tanto, é necessário ter presente:

Art. 55 I - a compreensão da globalidade da pessoa, enquanto ser que aprende, que sonha e ousa, em busca de uma convivência social libertadora fundamentada na ética cidadã;

\| - a superação dos processos e procedimentos burocráticos, assumindo com pertinência e relevância: os planos pedagógicos, os objetivos institucionais e educacionais, e as atividades de avaliação contínua;

III - a prática em que os sujeitos constitutivos da comunidade educacional discutam a própria práxis pedagógica impregnando-a de entusiasmo e de compromisso com a sua própria comunidade, valorizando-a, situando-a no contexto das relações sociais e buscando soluções conjuntas;

IV - a construção de relações interpessoais solidárias, geridas de tal modo que os professores se sintam estimulados a conhecer melhor os seus pares (colegas de trabalho, estudantes, familias), a expor as suas ideias, a traduzir as suas dificuldades e expectativas pessoais e profissionais;

$V$ - a instauração de relações entre os estudantes, proporcionando-thes espaços de convivência e situaç̃os de aprendizagem, por meio dos quais aprendam a se compreender e se organizar em equipes de estudos e de práticas esportivas, artísticas e politicas;

$\mathrm{VI}$ - a presença articuladora e mobilizadora do gestor no cotidiano da escola e nos espaços com os quais a escola interage, em busca da qualidade social das aprendizagens que the caiba desenvolver, com transparência e responsabilidade. (BRASIL, 2010b).

A incursão nos dispositivos legais supracitados nos permite constatar a existência de vários enfoques relativos à gestão democrática, entre os quais destacamos: a inclusão da gestão como um dos princípios a serem observados no ensino (BRASIL, 1988, 1996); a institucionalização do regime de colaboração (BRASIL, 2010b); a responsabilidade por sua regulamentação ao encargo dos sistemas de ensino (BRASIL, 1988, 1996); a promoção da gestão democrática (BRASIL, 2014); os integrantes da comunidade escolar como partícipes na gestão (BRASIL, 1996, 2010b); os dispositivos que requerem a participação da comunidade escolar, enfatizando-se a primazia do Projeto Político-Pedagógico, o qual se articula com o 
Regimento Escolar (BRASIL, 2010b, 2014); a existência de um plano de gestão no qual conste o modo de avaliação institucional (BRASIL, 2010b); a relação entre gestão e organização curricular (BRASIL, 2010b).

Diante disso, é possível constatar a polissemia e multidimensionalidade do conceito de gestão democrática nos dispositivos analisados (BRASIL, 2015). Dito de outra forma, na nossa visão há uma lacuna nos dispositivos legais consultados em termos de definição do significado da gestão democrática, abrindo possibilidades para múltiplas interpretações. Tais possibilidades são favorecidas pela própria legislação quando delega a cada sistema de ensino a responsabilidade de definir as normatizações acerca da gestão democrática. Se, por um lado, tal responsabilização descentraliza o poder decisório, por outro, pode conduzir a tomada de decisões contrárias à perspectiva democrática.

Ao refletirmos sobre alguns referenciais acerca da gestão democrática na escola, recorremos a Lück (2009, p. 69-70), quando a autora destaca que a escola democrática

\begin{abstract}
[...] é aquela em que os seus participantes estão coletivamente organizados e compromissados com a promoção de educação de qualidade para todos. A democracia constitui-se em característica fundamental de sociedades e grupos centrados na prática dos direitos humanos, por reconhecerem não apenas o direito de as pessoas usufruírem dos bens e dos serviços produzidos em seu contexto, mas também, e sobretudo, seu direito e seu dever de assumirem responsabilidade pela produção e melhoria desses bens e serviços. Com essa perspectiva, direitos e deveres são dois conceitos indissociáveis, de modo que, falando-se de um, remete-se ao outro necessariamente. E é nessa junção que se estabelece a verdadeira democracia, construída mediante participação qualificada pela cidadania e construção do bem comum.
\end{abstract}

A responsabilidade última da gestão da escola e a liderança da equipe de gestão recai sobre a figura do gestor (BRASIL, 2010b), sendo que suas atribuições, no nosso entender, são descritas de forma superficial nos dispositivos legais. Lück (2013b, p. 16), ao se referir ao diretor, esclarece que:

Devido à sua posição central na escola, o desempenho de seu papel exerce forte influência (tanto positiva como negativa) sobre todos os setores e pessoas da escola. É do seu desempenho e de sua habilidade em influenciar o ambiente que dependem, em grande parte, a qualidade do ambiente e o clima escolar, o desempenho do seu pessoal e a qualidade do processo ensino-aprendizagem. 
Outro aspecto a destacar são os modos de condução do diretor a esse cargo. Para termos uma visão geral sobre esse aspecto, consultamos dados presentes no Plano Nacional de Educação PNE 2014-2024: Linha de Base (BRASIL, 2015), no que se refere à meta 19, cujo foco é a gestão democrática. Tais dados foram elaborados a partir dos microdados do Questionário do Diretor lapenas das escolas públicas, aplicados na Prova Brasil e Aneb no ano de 2013, contemplando 54.746 escolas, equivalente a $36 \%$ do total de 151.880 escolas públicas de Educação Básica). Prevalece a forma de indicação (técnica, política ou de outro tipo para o cargo), sendo esta indicada por $45,6 \%$ dos respondentes (BRASIL, 2015). Assim como Lück (2006, p. 77), entendemos que:

[...] não é a eleição em si, como evento, que democratiza, mas sim o que
ela representaria como parte de um processo participativo global, no qual
ela corresponderia apenas a um momento de culminância num processo
construtivo e significativo para a escola. Ao se promover a eleição de
dirigentes estar-se-ia delineando uma proposta de escola, um estilo de
gestão e se firmando compromissos coletivos para levá-los a efeito de
forma efetiva.

A Lei de Diretrizes e Bases, ao tratar da formação requerida para o exercício da função, enfatiza o preparo para o "Art. 64 [...] planejamento e a administração da escola." (BRASIL, 1996). Ao fazermos tal destaque, queremos trazer à tona a necessidade de haver uma distinção entre administração e gestão. No entender de Lück (2006, p. 23), o conceito de gestão "supera o enfoque limitado de administração, a partir do entendimento de que os problemas educacionais são complexos, em vista do que demandam visão global e abrangente, assim como ação articulada, dinâmica e participativa." Continua a autora explicando que:

\footnotetext{
Assenta-se, portanto, sobre a mobilização dinâmica e em equipe do elemento humano, coletivamente organizado [...] A gestão emerge para superar, dentre outros aspectos, carência: a) de orientação e de liderança clara e competente, exercida a partir de princípios educacionais democráticos e participativos; b) de referencial teórico-metodológico avançado para a organização e orientação do trabalho em educação; c) de uma perspectiva de superação efetiva das dificuldades cotidianas pela adoção de mecanismos e métodos estratégicos globalizadores para a superação de seus problemas. (LÜCK, 2006, p. 23-24).
}

Quanto à composição da equipe de gestão, não identificamos nos dispositivos nenhuma menção à sua configuração, o que, de certa forma, parece-nos contraditório dentro de uma perspectiva democrática. Para Lück (2009, p. 22): “0s gestores escolares, constituídos em uma equipe de gestão, são os profissionais responsáveis pela organização e orientação 
administrativa e pedagógica da escola, da qual resulta a formação da cultura e o ambiente escolar." Continua a autora:

\begin{abstract}
Em caráter abrangente, a gestão escolar engloba, de forma associada, o trabalho da direção escolar, da supervisão ou coordenação pedagógica, da orientação educacional e da secretaria da escola, considerados participantes da equipe gestora da escola. Segundo o princípio da gestão democrática, a realização do processo de gestão inclui também a participação ativa de todos os professores e da comunidade escolar como um todo, de modo a contribuirem para a efetivação da gestão democrática que garante qualidade para todos os alunos. (LUCK, 2009, p. 23).
\end{abstract}

Sobre as instâncias de participação e respectivos participantes, os dispositivos mencionam os profissionais da educação e a comunidade escolar e local em conselhos escolares ou equivalentes (BRASIL, 1996). Vale destacar que:

\begin{abstract}
Um órgão colegiado escolar constitui-se em um mecanismo de gestão da escola que tem por objetivo auxiliar na tomada de decisão em todas as suas áreas de atuação, procurando diferentes meios para se alcançar o objetivo de ajudar o estabelecimento de ensino, em todos os seus aspectos, pela participação de modo interativo de pais, professores e funcionários. [...] (LÜCK, 2006, p. 66).
\end{abstract}

Nos dispositivos legais há um acento na participação da comunidade escolar na elaboração da Proposta Pedagógica (BRASIL, 1996, 2010b). Contudo, dados apresentados no Plano Nacional de Educação PNE 2014-2024: Linha de Base apontam que:

No que se refere ao projeto pedagógico da escola, foi possivel captar, de forma mais clara, a participação da equipe escolar, embora não possa ser percebida a de pais e alunos na atividade. Assim, 89,1\% das escolas afirmaram contar com algum tipo de discussão com a equipe escolar acerca do desenvolvimento do projeto pedagógico. (BRASIL, 2015, p. 322).

Com relação ao Conselho Escolar, os dados apresentados no referido documento indicam que:

No que diz respeito ao Conselho Escolar, duas questões foram analisadas: a primeira se refere à frequência de reuniões desse órgão colegiado e a segunda à sua composição. Quanto à frequência com que se reúne, os dados [...] mostram que $64,4 \%$ das escolas possuiam conselho escolar que se reunia três vezes ou mais por ano, $17 \%$ duas vezes e $5,8 \%$ uma vez ou 
mais. Chama a atenção, no entanto, o fato de que havia $10,6 \%$ de escolas públicas sem Conselho Escolar e 2,3\% dos conselhos existentes não se reuniram nenhuma vez. (BRASLL, 2015, p. 324).

Esses dados apresentados sobre a preponderância da participação da equipe escolar na Proposta Pedagógica e os atinentes ao Conselho Escolar suscitam a reflexão de que uma gestão democrática requer que "os membros do órgão colegiado sejam apenas o ponto de partida, para que todos os pais se envolvam com os trabalhos da escola, cabendo aos primeiros buscar os meios para promover esse envolvimento." (LÜCK, 2006, p. 67). Ou seja, a existência de um Conselho Escolar não é garantia de participação efetiva.

Chama-nos a atenção a ausência de referência, nos dispositivos, a outras instâncias de participação na gestão da escola, além do Conselho Escolar, como o Grêmio Estudantil, enquanto uma

Entidade que representa o conjunto dos estudantes de uma escola e possibilita a discussão sobre seus problemas e desafios, gerais ou específicos. Cabe ao Grêmio desenvolver as lutas locais e promover a integração dos estudantes através de atividades culturais e acadêmicas. Representa os estudantes de cada escola nos fóruns gerais do movimento estudantil secundarista e promove o diálogo com as entidades gerais (Uniões Estaduais e UBES). Realizam eleições anuais e também assembleias gerais. (GRÊMIO LIVRE-SENADO FEDERAL, 2017, p. १३).

A Lei n. 7.398, de 4 de novembro de 1985 assegura "Art. $1^{\circ}$ [...] a organização de estudantes como entidades autônomas representativas dos interesses dos estudantes secundaristas com finalidades educacionais, culturais, cívicas esportivas e sociais." (BRASIL, 1985). Os estudantes se constituem em sujeitos da educação e, dessa forma, enquanto integrantes da comunidade escolar, possuem o direito de participar das decisões nesse contexto. 0 incentivo à liderança de turma também é fundamental, pois viabiliza o exercício da democracia e da cidadania desde a mais tenra idade (BRASIL, 2010b).

Com relação à organização e ao planejamento da ação gestora, constatamos lacunas nos dispositivos acerca dessas dimensões. Embora haja indicativos gerais na Lei de Diretrizes e Bases (BRASIL, 1996) e a sugestão de um plano de gestão nas Diretrizes Curriculares (BRASIL, 2010b), atrelado à questão da avaliação institucional, consideramos que seria necessária maior ênfase sobre essas dimensões.

A organização e o planejamento da ação gestora devem se direcionar para ○ conjunto global da escola, articulando as questões administrativas e pedagógicas. Apesar de a Lei de Diretrizes e Bases (BRASIL, 1996) sinalizar para essas duas questões, ainda assim 
nos parece que os indicativos apresentados em tal dispositivo reduzem a complexidade da ação gestora. Segundo Libâneo, Oliveira e Toschi (2003, p. 293, grifo do autor):

\begin{abstract}
No caso da escola, a organização e a gestão referem-se ao conjunto de normas, diretrizes, estrutura organizacional, ações e procedimentos que asseguram a racionalização do uso de recursos humanos, materiais, financeiros e intelectuais, assim como a coordenação e o acompanhamento do trabalho das pessoas. Por racionalização do uso de recursos compreende-se a escolha racional de meios compativeis com os fins visados e a adequada utilização desses recursos, que assegure a melhor realização desses fins. Por coordenação e acompanhamento compreendemse as ações e os procedimentos destinados a reunir, a articular e a integrar as atividades das pessoas que atuam na escola, para alcançar objetivos comuns. Para que essas duas características mais gerais de uma instituição se efetivem são postas em ação as funções específicas de planejar, organizar, dirigir e avaliar. A condução dessas funções, mediante várias ações e procedimentos é o que se designa gestão, a atividade que põe em ação um sistema organizacional.
\end{abstract}

A visão apresentada pelos autores supracitados sinaliza para a amplitude do ato da organização e do planejamento da ação gestora, o que requer do gestor um olhar abrangente sobre a escola, como já referimos, em suas dimensões administrativa e pedagógica. De acordo com Lück (2014, p. 102-103):

Verifica-se, infelizmente, não ser incomum o diretor escolar e sua equipe estarem mais voltados para uma orientação meramente administrativa, de organização de recursos e controle burocrático do trabalho educacional, do que de gestão e liderança de pessoas, portanto, seguindo uma linha de atuação limitada e superada, em relação aos paradigmas atuais e concepção da educação voltada para a formação plena de pessoas no contexto da sociedade do conhecimento.

Entendemos que um olhar abrangente acerca do contexto escolar pode ser viabilizado por meio do diagnóstico, o qual pode ser favorecido pela avaliação institucional. Ao contrário do que alguns pensam, esta avaliação "é muito mais do que a prática de coleta de dados e informações a apresentações de relatórios correspondentes" (LÜCK, 2012, p. 27), pois ela deve estar a "serviço da gestão escolar, uma vez que esta se constitui no trabalho de organização, orientação e mobilização de esforços e recursos escolares para promover o trabalho educacional com a máxima efetividade possível." (LÜCK, 2012, p. 28).

De posse do diagnóstico realizado e da sua análise com os integrantes da comunidade escolar, tendo como referência a Proposta Pedagógica da escola, a equipe gestora terá subsídios para propor coletivamente um conjunto de metas, indicadores, ações 
e forma de monitoramento dos resultados que integrarão o plano de gestão. Esse plano de gestão será o documento norteador da ação gestora no espaço temporal definido por essa equipe. Retomando Lück (2012, p. 31):

\begin{abstract}
Vale dizer que a avaliação institucional, como instrumento de gestão, corresponde a um processo que se integra ao planejamento educacional, dele emergindo e a ele remetendo, como também a processos de monitoramento que acompanham objetivamente as práticas educacionais, estabelecendo relações entre estas e os seus resultados, contribuindo dessa forma para apontar transformações e correções de rumos necessários durante a sua condução, de modo a garantir sua maior efetividade.
\end{abstract}

Reiteramos que a elaboração de um plano de gestão é essencial para que se atinjam as finalidades e os objetivos educacionais, sendo que "o processo e o exercício de planejar referem-se a uma antecipação da prática, de modo a prever e programar as ações e os resultados desejados, constituindo-se numa atividade necessária à tomada de decisões." (LIBÂNEO, 2004, p. 149).

Conforme referido, a gestão escolar está articulada à gestão educacional e viceversa. Dessa forma, a gestão democrática também requer a participação dos profissionais da educação, entre eles os gestores, na tomada de decisões no âmbito macro, relativas a políticas, programas, planos e ações educacionais que incidem no fazer educativo cotidiano das escolas. Desse ponto de vista,

A gestão participativa se assenta, portanto, no entendimento de que o alcance dos objetivos educacionais, em seu sentido amplo, depende da canalização e do emprego adequado da energia dinâmica das relações interpessoais ocorrentes no contexto de sistemas de ensino e escolas, em torno de objetivos educacionais, concebidos e assumidos por seus membros, de modo a constituir um empenho coletivo em torno de sua realização. (LÜCK, 2013a, p. 22).

Existem diferentes níveis de participação, sendo que "o engajamento representa o nível mais pleno, [pois] implica envolver-se dinamicamente [...] e assumir responsabilidade por agir com empenho, competência e dedicação visando promover os resultados propostos e desejados." (LÜCK, 2013a, p. 47). Assim, "a organização escolar democrática implica não só a participação na gestão, mas a gestão da participação." (LBÂANE0, 2004, p. 143, grifo do autor).

Por fim, cabe enfatizar que a constatação de lacunas nos dispositivos analisados atinentes às questões que nos propomos a aprofundar sinaliza que tais dispositivos precisam ser aprofundados, interpretados e traduzidos para a realidade de cada contexto educativo. 


\section{CONSIDERAÇÕES FINAIS}

Os principais achados do estudo são sistematizados em dois tópicos: desafios e perspectivas. Quanto aos desafios, destacamos a necessidade da consolidação de uma cultura escolar pautada pelo diálogo, pela participação e pela corresponsabilidade dos que integram uma comunidade educativa.

Nas palavras de Lück (2006, p. 42), "os ideais democráticos que devem orientar a educação, a fim de que contribua para a correspondente formação de seus alunos, necessitam de ambiente democrático e participativo." Isso implica tornar o contexto escolar um espaço em que seja possível o exercício da democracia, concebida dentro do ideário de um Estado Democrático de Direito. Exercício esse que precisa ser realizado: a) pela equipe de gestão escolar, ao organizar e planejar a ação gestora, tendo-se presente a finalidade e os objetivos educacionais; a identidade escolar e as especificidades do fazer profissional de cada um que integra tal equipe; a promoção de espaços e tempos para a participação dos integrantes da comunidade escolar nos processos decisórios; b) pelos professores, por meio das diversas situações de aprendizagem propostas no decorrer do itinerário formativo dos estudantes, o qual é orientado por um currículo; c) pelos estudantes e seus responsáveis, assumindo a corresponsabilidade no processo formativo, com a gestão da escola e com a qualidade educacional; e d) pelas relações que se estabelecem entre os integrantes da comunidade escolar.

Nesse sentido, "é possível fazer avançar as práticas, o entendimento sobre elas e o nível de consciência das pessoas envolvidas, que, por suas vivências, tornam-se sujeitos de sua atuação, evoluindo, ao mesmo tempo em que promovem evolução das organizações sociais que participam." (LÜCK, 2006, p. 40).

No que se refere às perspectivas, enfatizamos que a gestão democrática pode se constituir numa dimensão mobilizadora das competências dos diversos atores que compõem a comunidade educativa, contribuindo para que haja sinergia entre eles, tendo em vista a consolidação da educação de qualidade. Diante disso, "a democratização da escola corresponderia, portanto, à realização do trabalho escolar orientado pela realização e o desenvolvimento da competência de todos, em conjunto." (LÜCK, 2006, p. 61).

Assim, "a democracia se expressa como condição fundamental para que a organização escolar se traduza em um coletivo atuante, cujos deveres emanam dele mesmo, a partir de sua maturidade social, e se configuram em sua expressão e identidade que se renova e se supera continuamente." (LÜCK, 2013a, p. 56). 


\section{REFERÊNCIAS}

BARDIN, L. Análise de Conteúdo. São Paulo: Edições 70, 2011.

BRASIL. Constituição. República Federativa do Brasil de 1988. Brasília, DF: Senado Federal, 1988.

BRASIL. Lei n. 7.398, de 4 de novembro de 1985. Dispõe sobre a organização de entidades representativas de estudantes. Brasilia, DF, 4 nov. 1985. Disponível em http://www.planalto.gov.br/ccivil_03/ leis/17398.htm. Acesso em: 28 out. 2019.

BRASIL. Lei n. 8.069, de 13 de julho de 1990. Dispõe sobre o Estatuto da Criança e do Adolescente e dá outras providências. Diário Oficial da União, Brasília, DF, 16 jul. 1990.

BRASIL. Lei n. 9.394, de 20 de dezembro de 1996. Estabelece as diretrizes e bases da educação nacional. Diário Oficial da União, Brasília, DF, 23 dez. 1996.

BRASIL. Ministério da Educação. Base Nacional Comum Curricular. Brasília, DF: MEC, 2017.

BRASIL. Ministério da Educação. Conselho Nacional de Educação. Parecer CNE/CEB n. 7, de 7 de abril de 2010. Diretrizes Curriculares Gerais para a Educação Básica. Brasília, DF, 7 abr. 2010a.

BRASIL. Ministério da Educação. Conselho Nacional de Educação. Câmara de Educação Básica. Resolução n. 4, de 13 de julho de 2010. Define Diretrizes Curriculares Nacionais Gerais para a Educação Básica, DF, 2010b.

BRASIL. Ministério da Educação. Conselho Nacional de Educação. Câmara de Educação Básica. Resolução n. 5, de 17 de dezembro de 2009. Fixa as Diretrizes Curriculares Nacionais para a Educação Infantil. Diário Oficial da União: seção 1, Brasília, DF, p. १८, १८ dez. 2009.

BRASIL. Ministério da Educação. Conselho Nacional de Educação. Câmara de Educação Básica.

Resolução n. 7, de 14 de dezembro de 2010. Fixa Diretrlonuizes Curriculares Nacionais para o Ensino Fundamental de 9 (nove) anos. Brasilia, DF, 14 dez. 2010c.

BRASIL. Ministério da Educação. Diretrizes Curriculares Nacionais Gerais da Educação Básica. Brasilia, DF: MEC, SEB, DICEI, 2013.

BRASIL. Plano Nacional de Educação PNE 2014-2024: Linha de Base. Brasília, DF: Inep, 2015.

BRASIL. Presidência da República. Casa Civil. Subchefia para assuntos jurídicos. Lei n. 13.005, de 25 de junho de 2014. Aprova o Plano Nacional de Educação- PNE e dá outras providências. Brasília, DF, 25 jun. 2014.

GIL, A. C. Métodos e Técnicas em Pesquisa Social. 6. ed. São Paulo: Atlas, 2008. 
GODOY, A. S. Pesquisa qualitativa: tipos fundamentais. Revista Administração de Empresas, v. 35, n. 3, p. 20-29, 1995.

GRÊMIO LIVRE-SENADO FEDERAL. Disponivel em http://www2.senado.leg.br/bdsf/bitstream/handle/ id/385450/Gremio\%20Livre.pdf?sequence=Acesso em: 30 dez. 2017.

LIBÂNEO, J. C. Organização e gestão da escola: teoria e prática. 5. ed. Goiânia: Editora Alternativa, 2004.

LIBÂNEO, J. C.; OLIVEIRA, J. F. de; TOSCH, Mirza Seabra. Educação escolar: políticas, estrutura e organização. São Paulo: Cortez, 2003.

LÜCK, H. A gestão participativa na escola. 11. ed. Rio de Janeiro: Editora Vozes, 2013a.

LÜCK, H. Ação integrada: administração, supervisão e orientação educacional. 29. ed. Rio de Janeiro: Editora Vozes, 2013b.

LÜCK, H. Concepções e processos democráticos de gestão educacional. 9. ed. Rio de Janeiro: Editora Vozes, 2006.

LÜCK, H. Dimensões de gestão escolar e suas competências. Curitiba: Editora Positivo, 2009.

LÜCK, H. Gestão educacional: uma questão paradigmática. १2. ed. Rio de Janeiro: Editora Vozes, 2016.

LÜCK, H. Liderança em gestão escolar. 9. ed. Rio de Janeiro: Editora Vozes, 2014.

LÜCK, H. Perspectivas da avaliação institucional da escola. Rio de Janeiro: Editora Vozes, 2012.

MEDEIROS, I. L. P. de; LUCE, M. B. Gestão Democrática na e da educação: concepções e vivências. In: LUCE, M. B.; MEDEIROS, I. L. P. de (org.). Gestão escolar democrática: concepções e vivências. Porto Alegre: Ed. da UFRGS, 2006. p. 15-25.

MOROZ, M.; GIANFALDONI, M. H. T. A. 0 Processo de Pesquisa: iniciação. 2. ed. Brasília, DF: Liber Livro Editora, 2006.

ORGANIZAÇÃO DAS NAÇÕES UNIDAS. Declaração Universal dos Direitos Humanos. [S. l.: s. n., 1948.

ORGANIZAÇÃO DAS NAÇÕES UNIDAS PARA A EDUCAÇÃO, A CIÊNCIA E A CULTURA. Declaração Mundial sobre Educação para Todos: satisfação das necessidades básicas de aprendizagem. Jomtien, 1990.

ORGANIZAÇÃO DAS NAÇÕES UNIDAS PARA A EDUCAÇÃO, A CIÊNCIA E A CULTURA. Declaração de Incheon Educação 2030: rumo a uma educação de qualidade inclusiva e à educação ao longo da vida para todos. [S. l]: Unesco, 2015a. 
ORGANIZAÇÃO DAS NAÇÕES UNIDAS PARA A EDUCAÇÃO, A CIÊNCIA E A CULTURA. Marco de Ação - Educação 2030: rumo a uma educação de qualidade inclusiva e à educação ao longo da vida para todos. [S. l.: Unesco, 2015b.

ORGANIZAÇÃO DAS NAÇÕES UNIDAS PARA A EDUCAÇÃO, A CIÊNCIA E A CULTURA. Educação para Todos: o Compromisso de Dakar. Brasília, DF: Unesco, Consed, Ação Educativa, 2001.

ORGANIZAÇÃO DOS ESTADOS IBERO-AMERICANOS PARA A EDUCAÇÃO, A CIÊNCIA E A CULTURA. Metas Educativas 2021: a educação que queremos para a geração dos bicentenários. Brasília, DF: [s. n., 2012.

SÁ-SILVA, J. R.; ALMEIDA, C. D.; GUINDANI, J. F. Pesquisa documental: pistas teóricas e metodológicas. Revista Brasileira de História \& Ciências Sociais, [s. l], n. 1, p. 1-15, jul. 2009.

Endereços para correspondência: Dirléia Fanfa Sarmento. Av. Victor Barreto, 2288, Centro, 92010-000, Canoas, Rio Grande do Sul, Brasil; dirleia.sarmento@unilasalle.edu.br

Roteiro, Joaçaba, U. 45, p. 1-20, jan./dez. 2020 | e23370 |E-ISSN 2177-6059 
